\title{
PERBANDINGAN PENERAPAN KEBIJAKAN PENDIDIKAN INDONESIA DENGAN FINLANDIA
}

\author{
Faradiba, Septina Severina Lumbantobing
}

Surel: faradiba@uki.ac.id

\begin{abstract}
In the process, educational programs that have been previously planned do not always run as planned, so that there is often a policy to solve the latest problems in order to achieve the goal of achieving equal and quality education in accordance with what is mandated in the law. Indonesia as a developing country is deemed necessary to adopt an education system that has been successfully implemented in other countries. Currently, one of the countries that can be used as a reference in the education sector is Finland. This research uses meta-analysis design. The results of this study there are several aspects that can be implemented from existing educational policies in the country of Finland to Indonesia. With an increase in the quality of education in the country of Indonesia is expected to be able to give birth to future generations who can compete internationally.
\end{abstract}

Keywords: Education Policy, Finland, Quality of Education.

\begin{abstract}
ABSTRAK
Dalam prosesnya, program-program pendidikan yang telah di rencanakan sebelumnya tidak selalu berjalan sesuai dengan yang direncanakan, sehingga kerap kali muncul suatu kebijakan untuk menyelesaikan permasalahan terkini guna mencapai tujuan mencapai pendidikan yang merata dan berkualitas sesuai dengan yang diamanatkan dalam undang-undang. Indonesia sebagai negara berkembang dirasa perlu untuk mengadopsi sistem pendidikan yang sudah berhasil diimplementasikan di negara lain. Saat ini salah salah satu negara yang dapat dijadikan acuan di bidang pendidikan antara lain Finlandia. Penelitian ini menggunakan desain meta analisis. Hasil dari penelitian ini terdapat beberapa aspek yang dapat diimplementasikan dari kebijakan pendidikan yang ada di negara Finlandia ke Indonesia. Dengan adanya peningkatan kualitas mutu pendidikan di negara Indonesia diharapakan mampu melahirkan generasi penerus yang dapat bersaing pada dunia internasional.
\end{abstract}

Kata kunci : Kebijakan Pendidikan, Finlandia, Mutu Pendidikan.

\section{PENDAHULUAN}

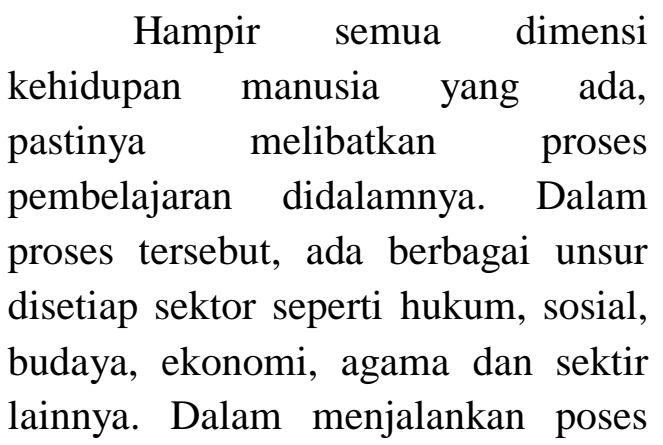

pembelajaran tersebut hendaknya mempertimbangkan unsur-unsur yang terkait, agar sasaran yang telah ditentukan oleh pemerintah dapat dijalankan benar, sesuai dengan tujuan yang ingin dicapai. Visi pendidikan nasional yang ada di indonesia adalah "meujudkan sistem pendidikan menjaid sebuah pranata 
sosial yang kuat dan berwibawa untuk dapat memberdayakan seluruh Warga Negara Indonesia yang diharapkan akan berkembang menjadi manusia yang berkualitas, sehingga mampu menjawab tantangan zaman yang selalu berubah-ubah". Dari ulasan tersebut, diperlukan suatu perencanaan atau program-program yang sesuai dalam arah peningkatan mutu pendidikan di Indonesia. Peningkatan mutu pendidikan secara nasional merupakan cita-cita seluruh pihak yang terlibat dalam pendidikan. Pendidikan dikatakan menjadi penting, karena adanya persaingan antar lembaga yang mengelola sektor pendidikan, maupun persaingan lembaga kerja. Dimasa sekarang ini, para calon pekerja apabila ingin memiliki peluang besar untuk dapat diterima di tempat yang mereka inginkan, hendaknya wajib membekali dirinya dengan pendidikan yang bermutu, sehingga dapat bersaing dengan calon pekerja lainnya yang memilih jenis pekerjaan yang sama. Selain itu, adanya kebijakan yang dibangun dan diterapkan oleh lembaga pendidikan bermaksud untuk memastikan mutu di institusi tersebut, sehingga mutu pendidikan akan berjalan sesuai yang diharapkan, bahkan melampaui standar yang sudah ditetapkan.

Peningkatan mutu pendidikan sangat erat kaitannya dengan strategi dan kebijakan yang dilakukan. Seperti: (i) Kesinambungan proses evaluasi (continuos improvement), (ii) Penentuan standar mutu pendidikan (quality assurance), (iii) Perubahan kultur pendidikan yang menyesuaikan dengan tuntutan zaman (change of culture), (iv) Upaya mempertahankan relasi dengan pelanggan (keeping close to the costumer). Berdasarkan strategi dan kebijakan tersebut, di satu bagian kebutuhan mutu pendidikan merupakan sebuah keniscayaan, tapi pada sisi yang lain permasalahanpermasalahan yang terjadi di sektor pendidikan secara nasional juga cukup kompleks.

Beberapa hambatan yang ditemui pada pelaksanaan pendidikan yang ada di Indonesia dapat berupa (Hasbullah, 2015): ketidakseimbangan daya tampung, (ii) pemerataan pendidikan, (iii) mutu pendidikan yang tidak maksimal, (iv) kualitas jan jumlah tenaga pendidik terbatas, (v) dana pendidikan, dan (vi) kesesuaian pendidikan ditiap daerah berbeda. Tidak sedikit terjadi pada masyarakat pedesaan keengganan untuk menyekolahkan anaknya, disamping faktor ekonomi, faktor kualitas pendidikan juga menjadi penyebab hal tersebut (Prasetyia, 2019). Terkait pemerataan pendidikan, selain kualitas antara pedesaan dan perkotaan, ketimpangan perhatian antara sekolah umum dan inklusif juga masih menjadi perhatian pemerintah (Oktadiana et all., 2018). Pada prakteknya, proses pendidikan yanga ada di indonesia terkadang berjalan tidak sesuai harapan, sehingga sering kali muncul suatu kebijakan untuk dapat menyelesaikan permasalahan terkini untuk mencapai tujuan pendidikan nasional yang merata dan berkualitas. 


\section{METODE PENELITIAN}

Riset ini menggunakan teknik Meta Analisis. Teknik ini merupakan analisis dari beberapa hasil analisis yang dilakukan oleh peneliti sebelumnya. Di dalam sebuah penelitian, meta analisis adalah sebuah kajian yang dilakukan dari sejumlah hasil penelitian sejenis dengan permasalahan yang diangkat sama. Pengumpulan data pada riset ini menggunakan teknik dokumentasi. Penentuan populasinya yaitu semua dokumen literatur-literatur terkait kebijakan pendidikan. Dokumen tertulis yang dimaksud pada penelitian ini seperti: artikel jurnal, buku dan penelitian-penelitian. Pengambilan sampel pada penelitian ini menggunakan teknik Purposive Sampling. Teknik pengambilan sampel tersebut dipilih agar data atau informasi yang didapatkan dari sampel penelitian ini memiliki kesesuaian dengan tema yang diangkat pada penelitian ini.

\section{HASIL PENELITIAN DAN PEMBAHASAN}

Indonesia sebagai negara berkembang dirasa perlu untuk mengadopsi sistem pendidikan yang sudah berhasil diimplementasikan di negara lain. Saat ini, salah salah satu negara yang dapat dijadikan acuan di bidang pendidikan antara lain Finlandia. Pendidikan di negara Finlandia dikenal termasuk sistem pendidikan terbaik yang ada di dunia. Namun siapa sangka dalam perjalanannya, pendidikan dinegara tersebut masih tergolong rendah pada tahun 1960-an. Ditahun tersebut, hanya ada satu dari sepuluh orang dewasa di Negara tersebut yang dapat menyelesaikan pendidikannya lebih dari Sembilan (9) tahun di tingkat pendidikan dasar. Pada tahun tersebut hanya beberapa yang mendapatkan gelar sampai pada perguruan tinggi (Sahlberg, 2011).

Di Negara Finlandia, pada tingkat perguruan tinggi untuk calon tenaga pendidik, sudah memiliki sekolah praktik yang nantinya sebagi tempat mahasiswa untuk melakukan internship. Pada proses internship, mahasiswa akan dibimbing oleh guru pendamping. Tugas dari dari guru pendamping tersebut melakukan supervisi pada saat mahasiswa melakukan pengajaran di sekolah. Guru pendamping dapat menggontrol serta mengevaluasi hasil praktek mengajar mahasiswa (Baskan et all., 2013). Berbeda dengan negara indonesia, meskipun mahasiswa sebagai calon guru melakukan praktik mengajar di sekolah, hanya saja peran guru pendamping ini menjadi penting, namun kurangnya keterlibatan guru pendamping mengkibatkan praktik mengajar di sekolah yang dilakukan oleh mahasiswa tidak berjalan ideal (Sunaryo, 2002).

Pada dasarnya pendidikan di indonesia tidak begitu berbeda seperti yang ada di Finlandia. Proses mahasiswa yang menjadi calon tenaga pendidik di Indonesia juga melewati pendidikan sama dengan di Finlandia untuk menjadi seorang guru. Di bangku perkuliahan calon tenaga pendidik sudah perlengkapi dengan 
kegiatan latihan praktik mengajar disekolah. Namun demikian, pada situasi ini jika di Finliandia, waktu serta tuntutan yang di minta sangat berbeda dan tentunya jauh lebih. Tidak hanya pada proses pendidikan calon guru di perguruan tinggi, hal yang menjadi kontras perbedaan kualitass pendidikan di Indonesia berbeda dengan Finlandia yaitu perhatian terhadap pendidikan calon guru secara berkelanjutan. Guru di negara Finlandia mempunyai hak untuk di sekolahkan ke tingkat yang lebih tinggi. Bahkan guru yang telah bergelar magister (S-2) mempunyai hak yang sama dengan tingkat dibawahnya untuk disekolahkan. Adanya kebijakan seperti ini pun tetap mewajibkan guru untuk wajib mengajar meskipun berstatus studi lanjut. Dan kebijakan ini disambut antusias oleh guru yang ada di Finlandia. Di saat tenaga pendidik menempuh pendidikan tersebut, tenaga pendidik dapat menjadi lebih fokus kepada mata pelajaran yang sudah menjadi konsentrasi atau spesifikasi akademiknya. Apabila kita melihat negara Indonesia masih banyaknya tenaga yang memperoleh gelar pendidikan sarjana (S-1) dan yang lebih dalam lagi tenaga pendidik bahkan ada yang berpendidikan tidak sesuai yang dipersyaratkan. Di negara Indonesia banyak lulusan dibidang pendidikan namun berkarir tidak pada bidang pendidikan (Leonard, 2015). Kegiatan pengembangan keprofesionalan tenaga pendidik dapat dillaksanakan seperti dalam bentuk meliputi diklat- diklat fungsional dan kegiatan pengembangan diri lainnya yang dilakukan tenaga pendidik, pengembangan karya inovatif, dan publikasi ilmiah (Windrawanto, 2015).

Kualifikasi akademik sebagai persyaratan utama minimal yang wajib dimiliki oleh tenaga pendidik di negara Indonesia yaitu minimal berpendidikan sarjana atau yang setara (DIV/S1) dengan latar belakang jurusan yang sesuai dengan mata pelajaran yang akan diajarkan di sekolah nantinya. Dari syarat tersebut calon tenaga pendidik berasal dari institusi yang telah terakreditasi nasional. Dan semua tenaga pendidik mengikuti pelatihan pada scope penugasannya masing-masing (Fastrup et all., 2011). Pada pelaksanaannya, masih kurang metratanya sebaran calon tenaga pendidik. Sehingga daerah-daerah marginal hanya mendapatkan tenaga pendidik dengan kualifikasi pendidikan yang relatif masih rendah (Heyward et all., 2017).

Pelaksanaan pelatihan dan pengembangan tenaga pendidik dapat meningkatkan pembelajaran siswa. Berdasarkan hal tersebut, pembelajaran siswa menjadi maksimal dikarenakan peningkatan pengetahuan guru terkait materi yang diajarkan setelah melewati pelatihan. Program pelatihan guru ini juga mendapat respon yang sangat baik dari guru (Fozdarm et all., 2007). Namum pada program pelatihan ini tidak dapat menanamkan kompetensi 
lain yang sifatnya softskill (Dhawan, 2014).

Proses seleksi tenaga di Finlandia sangat ketat karena profesi sebagai tenaga pendidik termasuk populer di negara ini. Terlihat dari banyaknya calon tenaga pendidik yang yang gugur seleksi dan hanya sedikit yang lulus menjadi tenaga pendidik (Finnish National Board of Education, 2012). Sistem seleksi dilakukan secara terbuka, selain itu evaluasi dilakukan mengikuti standar yang telah dibuat oleh pihak sekolah. Adanya sistem seleksi yang amat baik ini, dapat menghasilkan tenaga pendidik yang memiliki kualifikasi yang sangat baik dan professional. Berbeda dengan yang ada di Indonesia, selain peningkatan mutu tenaga pendidik, fokus pemerintah adalah pemenuhan jumlah tenaga pendidik untuk mengajar khususnya pada daerah pedesaan. Dalam menghasilkan tenaga pendidik yang berkualitas dan profesional, pemerinta juga menetapka sistem seleksi yang cukup ketat. Pemerintah melakukan seleksi secara nasional dan tidak ada campur tangan dari pemerintah daerah dan tidak diperbolehkannya merekrut guru honorer untuk skolah negeri. Proses seleksi tenaga pendidik honorer dilakukan sesuai dengan Surat Keputusan yang diterbitkan oleh pimpinan sekolah dinilai tidak sesuai dengan "Peraturan Pemerintah Nomor 48 Tahun 2005" dan "Peraturan Pemerintah Nomor 43 Tahun 2007". Saat ini pemerintah melakukan proses seleksi calon tenaga pendidik melalui seleksi Calon
Aparatur Sipil Negara (CASN) dan Pegawai Pemerintah dengan Perjanjian Kerja (PPPK) yang dilakukan secara terpusat dan dilakukan oleh Badan Kepegawaian Negara (Arifa et all., 2019).

Dari segi Penelitian guru, di negara Finlandia berkomitmen menerapkan pendidikan tenaga pendidik yang mengutamakan penelitian. Hal ini berarti bahwa konsep pendidikan dalam proses pengajaran sangat ditekankan terkait hasil penelitian. Berbeda dengan yang ada di Indonesia tenaga pendidik masih terfokus hanya pada visi dan misi pendidikan dan pengajaran, namun visi dan misi ilmiah yang terkait pada bentuk penulisan dan publikasi karya ilmiah masih sering terabaikan (Noorjannah, 2014).

Negara Finlandia juga terus mengupayakan tenaga pendidik untuk penguasaan keterampiran teknologi dan informasi dalam pengaplikasiannya untuk kegiatan pembelajaran (Petrelius et all., 2016). Di Indonesia masih terdapat tenaga pendidik yang masih kurang dalam pengimplementasian ICT dalam peningkatan kualitas pembelajaran, mayoritas tenaga pendidik ditingkat dasar dan menengah. Selain itu, kurangnya pelatihan ICT juga dapat menjadi kendala untuk tenaga pendidik di sekolah tingkat dasar (Syukur, 2014).

Terkait dengan pusat-pusat pelatihan tenaga pendidik menjadi suatu hal yang penting di Finlandia. Pusat pelatihan banyak terdapat di negara ini. Bahkan universitas 
Faradiba, Septina Severina Lumbantobing : Perbandingan ...

memfasilitasi adanya sarana pusat pelatihan untuk guru dalam mengembangkan proyek yang sedang dikerjakan. Dari kebijakan tersebut tenaga pendidik mampu mengekspolrasi secara detail dan dapat mengaplikasikan hasil kerja secara mandiri dan dapat menciptakan program kegiatan yang dilakukan dalam mencapai berbagai kompetensi (Niemi, 2015). Di Indonesia, pelatihan kepada tenaga pendidik masih terdapat kekurangan, seperti tenaga pengajar yang dianggap tidak kompeten oleh para peserta, sehingga materi sulit untuk dipahami (Mujizatullah et all., 2019).

Penambahan waktu dalam proses belajar mengajar yang terjadi di sekolah telah diterapkan pada jenjang pendidikan tingkat dasar dan tingkat menengah di Indonesia, berawal dari adanya isu sistem pembelajaran di sekolah yang menggunakan sistem full day school ditetapkan oleh pemerintah. Proses pembelajaran ini diperkuat sejak dikeluarkannya "Peraturan Menteri Pendidikan dan kebudayaan (Permendikbud) Nomor 23 Tahun 2017 tentang Hari Sekolah". Hari sekolah dilaksanakan selama delapan (8) jam sehari atau empat puluh (40) jam selama lima (5) hari dalam seminggu. Dengan berlakunya sistem full day school, akan berdampak pada peningkatan aktivitas siswa dengan siswa lainnya dan juga dengan tenaga pendidik beserta perangkat sekolah secara keseluruhan. Meningkatnya aktivitas sosial siswa memberikan pengaruh yang sangat baik dalam menguatkan karakter siswa (Battistich, 2011).

Konsep dari sistem full day school ternyata sudah lama di lakukan dibeberapa Negara seperti Singapura, Amerika Serikat, Korea Selatan, China, Jepang dan beberapa negara maju lainnya. Negara yang menerapkan sistem ini memiliki alasan berbeda-beda, seperti untuk mengurangi perbedaan kemampuan belajar antara siswa yang mengikuti dan yang tidak bimbingan belajar, selain itu alasan lain dari sistem pembelajaran ini ternyata dapat menekan tingginya persentasi kriminalitas yang dilakukan oleh anak usia sekolah (Winurini, 2016). Sistem ini memiliki keunggulan baik di aspek akademik maupun non akademik. Di tingkat pendidikan usia dini, sistem ini memiliki berdampak positif dalam peningkatan kemampuan membaca dan berhitung (Newberry et all., 2017). Siswa lebih aktif dan fleksibel berkatifitas di kelas dalam kegiatan belajar. Siswa juga dapat menggali lebih dalam terkait respon yang sesuai dengan minat dan bakat siswa. Di Indonesia keberhasilan siswa masih menitikberatkan pada keberhasilan siswa dalam mencerna materi yang diberikan oleh tenaga pendidik dalam bentuk ujian. Pada setiap jenjangnya siswa diuji melalui sistem Ujian Nasional, untuk menentukan kelayakan siswa untuk melanjutkan ke jenjang selanjutnya. Pada sistem Ujian Nasional yang berbentuk pilihan ganda memicu polemik di berbagai kalangan. Pilihan ganda 
dirasa tidak dapat menentukan tingkat pegetahuan siswa secara komprehensif (Setiawan et all., 2019).

Sistem full day school yang baru ini ternyata ditanggapi berbeda oleh orang tua/wali siswa. Perbedaan respon antara orang tua/wali siswa ini dikarenakan karakteristik yang dimiliki oleh tiap orang tua/wali siswa berbeda, sehingga wacana sistem pembelajaran ini banyak yang mendukung dan tidak sedikit juga yang tidak mendukung sistem ini diterapkan di Indonesia. Hal inilah yang menjadi salah satu faktor sistem pembelajaran ini sulit untuk diterapkan di Indonesia (Khusnaya, 2016). Beberapa pihak dari orang tua siswa yang tidak setuju dengan penerapan sistem ini sangat disayangkan. Terkait hal ini sangat penting orang tua terlibat aktif yang nantinya akan berdampak sejalan dengan pendidikan karakter yang akan diterima oleh siswa (Berkowitz, 2005). Secara praktenya, banyak sekolah swasta berbasis keagamaan yang menerapkan sistem full day school. Di pagi hari siswa fokus dengan pengetahuan agama, dan di siang hari siswa belajar pengetahuan umum sesuai dengan jenjangnya. Sehingga tidak sedikit masyarakat yang lebih memilih sekolah swasta dibanding sekolah negeri, sekalipun orang tua harus merogoh kocek lebih dalam pada sekolah swasta (Stern et all., 2014).

\section{SIMPULAN}

$\begin{array}{clc}\text { Terdapat } & \text { faktor yang } & \text { dapat } \\ \text { menentukan } & \text { kulaitas } & \text { mutu }\end{array}$ pendidikan, di dalam peningkatan mutu tersebut diperlukan strategi atau kebijakan tertentu. Kebijakan atau strategi yang dapat dikembangkan dapat berupa: (i) Perbaikan kualitas pendidikan yang dilakukan secara terus menerus, (ii) Menetapkan standar mutu pendidikan, (iii) Perubahan kultur (change of culture), (iv) Mempertahankan dan menjaga relasi terhadap pelanggan. Dari strategi tesebut, diharapkan kualitas mutu pendidikan yang menjadi citacita bangsa indonesia bukan lagi menjadi suatu keniscayaan.

Dalam prosesnya programprogram pendidikan yang ada sering ditemukan kendala-kendala pada proses pelaksanaannya, sehingga kerap kali muncul suatu kebijakan untuk menyelesaikan permasalahan terkini guna mencapai tujuan mencapai pendidikan yang merata dan berkualitas sesuai dengan yang diamanatkan dalam undang-undang. Indonesia sebagai negara berkembang dirasa perlu untuk mengadopsi sistem pendidikan yang sudah berhasil diimplementasikan di negara lain. Saat ini salah salah satu negara yang dapat dijadikan acuan di bidang pendidikan antara lain Finlandia. Titik berat keberhasilan pendidikan di negara Finlandia adalah kebijakan yang diterapkan kepada tenaga pendidik.

Beberapa upaya telah dilakukan program-program dalam peningkatan mutu pendidikan di Indonesia, namun ada baiknya untuk mengadopsi kebijakan atau program yang sudah maju kualitas 
pendidikannya. Pada Tahun 2017 Indonesia menerapkan sebuah sistem terkait hari sekolah, yakni sistem full day school. Sistem tersebut mendapat berbagai tanggapan yang beragam dari masyarakat. Hal ini disebabkan oleh Karakteristik orang tua siswa yang amat beragam. Terdapat beberapa aspek yang dapat diimplementasikan dari kebijakan pendidikan yang ada di Finlandia ke Indonesia. Melalui peningkatan kualitas pendidikan di Indonesia diharapakan mampu melahirkan generasi penerus yang dapat bersaing pada dunia internasional.

\section{DAFTAR RUJUKAN}

Baskan, G. A., Y1ldı, E. P., and Tok, G. 2013. Teacher Training System in Finland and Comparisans Related to Turkey. 2nd World Conference on Educational Technology Researches, Procedia Social and Behavioral Sciences 83: 1073 1076.

Battistich, V. 2011. Character Education, Prevention, and Positive Youth Development. University of Missouri, St. Louis.

Dhawan, S. 2014. In-Service Training of Teachers is not Valuable in Imparting Knowledge in Life Skills and Action Research. International Journal of Management and Social Sciences Research 3(1): 97-102.

Fastrup, A. E. and Samuels, S. J. 2011. What Research Has to Say About Reading Instruction (4th ed.). The International Reading Association.

Finnish National Board of Education. 2012. Teachers in FinlandTrusted Professionals. Education in Finland.

Hamid, Abdul. 2015. Implementasi Peraturan Bupati Penajam Paser Utara nomor 18 Tahun 2012 Tentang Penyelengaraan pendidikan Gratis Di Kelurahan Nenang Kecamatan Penajam Kabupaten Penajam Paser Utara, e-Journal Ilmu Pemerintahan, 3, (2) 2015 : 623635.

Hasbullah, M. 2015. Kebijakan Pendidikan: Dalam Perspektif Teori, Aplikasi, dan Kondisi Objektif Pendidikan di Indonesia. Depok: Raja Grafindo Persada.

Khusnaya, Q. 2016. Partisipasi Orang Tua dalam Program Full Day School di SD Islam Terpadu Insan Utama Bantul Yogyakarta. Skripsi tidak diterbitkan. Yogyakarta: Fakultas Ilmu Pendidikan Universitas Negeri Yogyakarta.

Leonard. 2015. Kompetensi Tenaga Pendidik di Indonesia: Analisis Dampak Rendahnya Kualitas SDM Tenaga pendidik dan Solusi Perbaikannya. Jurnal Formatif 5(3): 192-201, 2015.

Mujizatullah and Mustolehudin. 2019. Pelaksanaan Pendidikan dan Pelatihan Terhadap Kinerja Tenaga pendidik Madrasah di Kota Gorontalo. Jurnal Penelitian Pendidikan Agama 
dan Keagamaan, 17(3), 2019, 267-283.

Noorjannah, Lilies. 2014.

Pengembangan Profesionalisme

Tenaga pendidik Melalui

Penulisan Karya Tulis Ilmiah

Bagi Tenaga pendidik

Profesional di SMA Negeri 1

Kauman Kabupaten

Tulungagung. Jurnal Humanity.

Petrelius, M., Laakso, M. J.,

Jormanainen, I., and Sutinen, E.

2016. How to Improve K12

Teachers' ICT Competence in

Finland: The Joensuu Region

Case. ICT in Education in Global

Context: 229-252.

Sahlberg, P. 2011. The Professional

Educator: Lessons from Finland.

American Educator, Summer 2011: 34-38.

Sunaryo, P.V.M. 2002. Kendala

bimbingan pemantapan

kemampuan mengajar (PKM) PPD-II PGSD Universitas

Terbuka di eks Karesidenan Pekalongan. Laporan penelitian. Pondok Cabe: LP-PUSLITGA.

Syukur, I., S. 2014. Profesionalisme

Tenaga pendidik Dalam

Mengimplementasikan Teknologi

Informasi dan Komunikasi di

Kabupaten Nganjuk. Jurnal

Pendidikan dan Kebudayaan, Vol. 20, Nomor 2.

Winurini, S. 2016. Wacana

Penerapan Full Day School untuk Siswa SD dan SMP. Majalah Info Singkat Kesejahteraan Sosial, VIII (15): 9-12. 